\title{
Protective effect of nifedipine in myocardial ischemia assessed by phosphorus-31 nuclear magnetic resonance
}

\author{
T. J. C. Ruigrok, C. J. A. van Echteld, B. De KruijfF, C. Borst and F. L. Meijler \\ Department of Cardiology, University Hospital and Departments of Biochemistry and Molecular Biology, \\ State University, Utrecht, The Netherlands
}

* KEY WORDS: Phosphorus-31 nuclear magnetic resonance, myocardial ischemia, calcium antagonist, nifedipine, intracellular $\mathrm{pH}$, adenosine triphosphate, creatine phosphate.

- Calcium antagonists may protect the myocardium against the consequences of ischemia. Phosphorus-31 nuclear magnetic resonance ( ${ }^{31} P$ NMR) was used to study the effect of nifedipine on intracellular acidosis and high energy phosphate depletion during global ischemia. Isolated rat hearts were paced (300 beats/ min), perfused with a modified Tyrode solution for $30 \mathrm{~min}$, made totally ischemic for $30 \mathrm{~min}\left(37^{\circ} \mathrm{C}\right)$ and then reperfused for $30 \mathrm{~min}$. When required, nifedipine $(1 \mathrm{mg} / \mathrm{l})$ was added to the perfusion fluid $10 \mathrm{~min}$ before ischemia.

During ischemia intracellular pH fell from $7 \cdot 11 \pm 0.03$ (mean \pm S.E.M.) to $5 \cdot 88 \pm 0.04$ in the untreated hearts $(n=6)$, and from $7.11 \pm 0.03$ to $5.95 \pm 0.02$ in the treated hearts $(n=6)$. During the first $20 \mathrm{~min}$ of ischemia, intracellular $\mathrm{pH}$ was significantly higher in the treated than in the untreated hearts $(P<0 \cdot 001)$. $M y o c a r d i a l$ creatine phosphate (CP) content was depleted after 15 min of ischemia in the untreated hearts, and after $20 \mathrm{~min}$ of ischemia in the hearts treated with nifedipine. Myocardial adenosine triphosphate (ATP) content was depleted after 20 min of ischemia in the untreated hearts; ATP content in hearts that received nifedipine amounted to $23 \cdot 5 \pm 6 \cdot 2 \%$ of control after $30 \mathrm{~min}$ of ischemia. In contrast with the untreated hearts, the nifedipine-treated hearts showed a rapid recovery of CP content during reperfusion.

The results indicate that nifedipine protects the myocardium against the metabolic consequences of ischemia and reperfusion.

Myocardial ischemia evokes a variety of changes, including a depletion of endogenous high-energy phosphate stores ${ }^{[1]}$, intracellular acidosis[ ${ }^{[2]}$, accumulation of calcium ${ }^{[3]}$ and the development of contracture[1]. Nifedipine given prior to or at the onset of a period of ischemia has been shown to maintain tissue CP at ATP[4,5] and to prevent calcium accumulation and contracture[3]. In addition, nifedipine prevented the massive uptake of calcium 1 during reperfusion and promoted the recovery of myocardial contractility[3].

Phosphorus-31 nuclear magnetic resonance $\left({ }^{31} \mathrm{P}\right.$ NMR) is a non-destructive method permitting repetitive measurements of intracellular $\mathrm{pH}^{[6]}$ as well as the CP and ATP content ${ }^{[7]}$ in the isolated, intact heart. The present study was designed to test the effect of nifedipine on intracellular acidosis

Requests for reprints to: T. J. C. Ruigrok, Ph.D., Department of Cardiology, University Hospital, 3500 CG Utrecht; The Netherlands. and high-energy phosphate depletion in the isolated rat heart during $30 \mathrm{~min}$ of normothermic global ischemia.

\section{Materials and methods}

PERFUSION METHODS

Male Wistar rats that weighed $400-450 \mathrm{~g}$ were anesthetized with diethyl ether and heparinized. Their hearts were removed and subsequently perfused at $37^{\circ} \mathrm{C}$ using the Langendorff technique ${ }^{[8]}$ at a constant pressure of $10.0 \mathrm{kPa}(75 \mathrm{~mm} \mathrm{Hg})$. The perfusate had the following composition $(\mathrm{mmol} / \mathrm{l})$ : $\mathrm{NaCl}, 124 ; \mathrm{KCl}, 4 \cdot 7 ; \mathrm{CaCl}_{2}, 1.3 ; \mathrm{MgCl}_{2}, 1 \cdot 0$; $\mathrm{NaHCO}_{3}, \quad 24 \cdot 0 ; \quad \mathrm{Na}_{2} \mathrm{HPO}_{4}, 0.5 ;$ glucose, 11.0. After equilibration with $95 \% \mathrm{O}_{2}-5 \% \mathrm{CO}_{2}$, the $\mathrm{pH}$ was $7 \cdot 40 \pm 0 \cdot 05$. The heart rate was maintained at 300 beats/min by left ventricular pacing with a $\mathrm{KCl}$-wick electrode, connected to a Grass S88 stimulator. After $30 \mathrm{~min}$ of control perfusion, the 

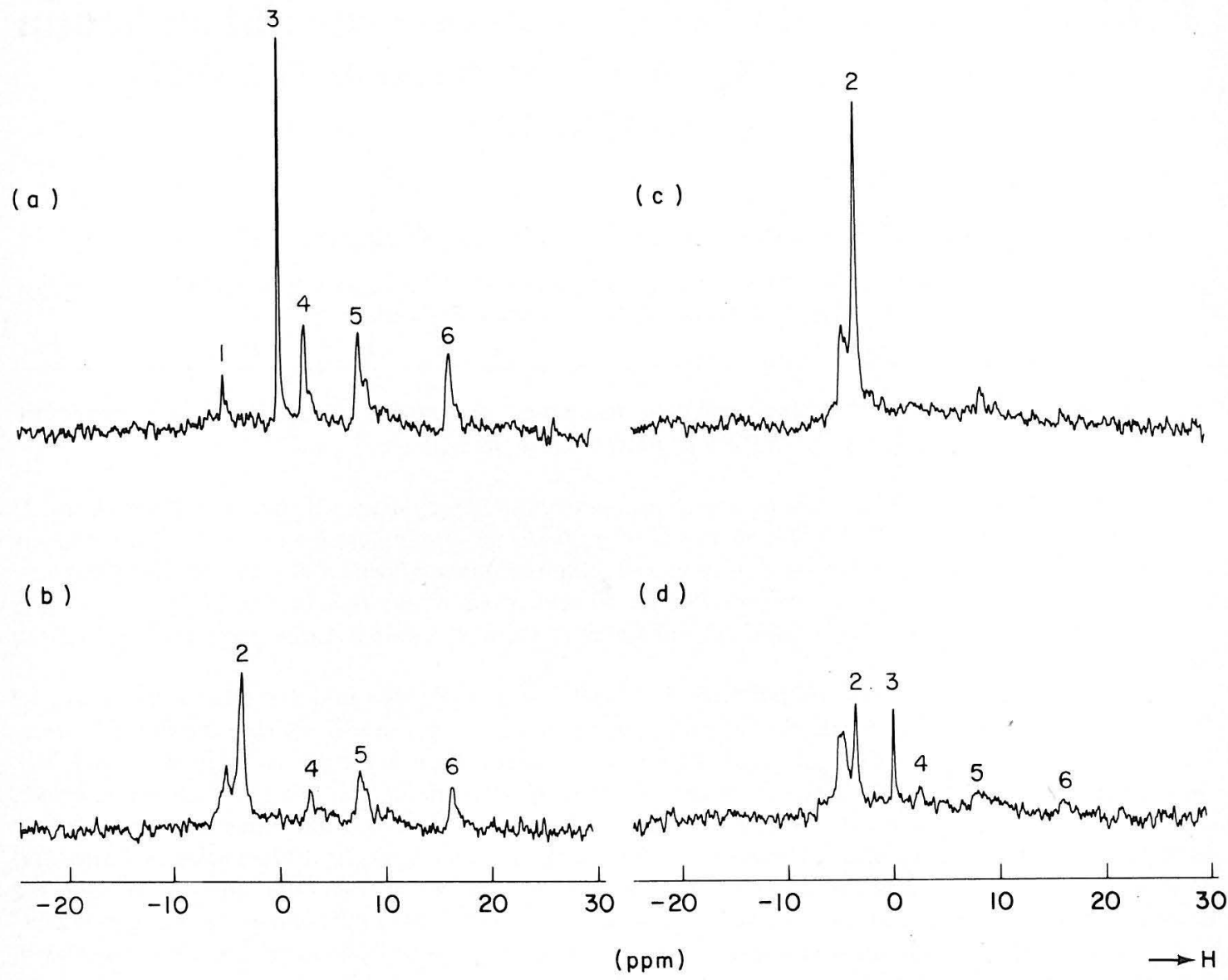

Figure 1 31P NMR spectra obtained (a) between 20 and $30 \mathrm{~min}$ of control perfusion, (b) between 5 and $15 \mathrm{~min}$ of total ischemia, (c) between 20 and $30 \mathrm{~min}$ of total ischemia and (d) between 20 and $30 \mathrm{~min}$ of reperfusion. The spectra were obtained from 260 radiofrequency pulses. The arrow indicates the direction of increasing field strength. Numbered peaks include (1) extracellular inorganic phosphate ( $\mathrm{Pi}(\mathrm{ext})),(2)$ intracellular inorganic phosphate (Pi(int)), (3) creatine phosphate (CP), and (4) the $\gamma-$, (5) $\alpha$-and (6) $\beta$-phosphate groups of adenosine triphosphate (ATP). Note the marked increase of the Pi(int) peak and the absence of the high-energy phosphate peaks at the end of the ischemic period.

hearts were made totally ischemic for $30 \mathrm{~min}$ and then reperfused for $30 \mathrm{~min}$. Myocardial temperature was maintained at $37^{\circ} \mathrm{C}$ throughout the experiment. When appropriate, nifedipine $(1 \mathrm{mg} / \mathrm{l})$ was added to the perfusion fluid $10 \mathrm{~min}$ before ischemia. Bayer AG (Leverkusen, F.R.G.) supplied ampoules containing a $0.1 \mathrm{mg} / \mathrm{ml}$ solution of nifedipine (solvent: ethanol/polyethylene glycol/water, $15 / 15 / 70)$. Care was taken that the nifedipinecontaining perfusate was not exposed to light[9].

\section{NUCLEAR MAGNETIC RESONANCE METHODS}

Spectra of ${ }^{31} \mathrm{P}$ NMR at $81.0 \mathrm{MHz}$ were recorded without proton decoupling and ${ }^{2} \mathrm{H}$-lock on a Bruker
WP200 spectrometer using a $5 \mathrm{kHz}$ spectral width, a $90^{\circ}$ pulse angle, an acquisition time of $0.82 \mathrm{~s}$ and a pulse repetition rate of $2 \cdot 32 \mathrm{~s}$. Accumulated free induction decays were obtained from 130 or 260 transients on submerged rat hearts in a total volume of $10 \mathrm{ml}$ in $20 \mathrm{~mm}$ tubes and exponentially multiplied resulting in $10 \mathrm{~Hz}$ line broadening. Zero $\mathrm{ppm}$ was assigned to the resonance position of $\mathrm{CP}$ at $\mathrm{pH} 7 \cdot 0$.

Intracellular $\mathrm{pH}$ was measured from the chemical shift of the Pi(int) peak, using a titration curve obtained from a solution containing ATP (10 $\mathrm{mmol} / \mathrm{l}), \mathrm{CP}(10 \mathrm{mmol} / \mathrm{l}), \mathrm{Pi}(10 \mathrm{mmol} / \mathrm{l})$, NADPH (10 mmol/l), glucose-6P $(10 \mathrm{mmol} / \mathrm{l})$, and $\mathrm{MgCl}_{2}$ 


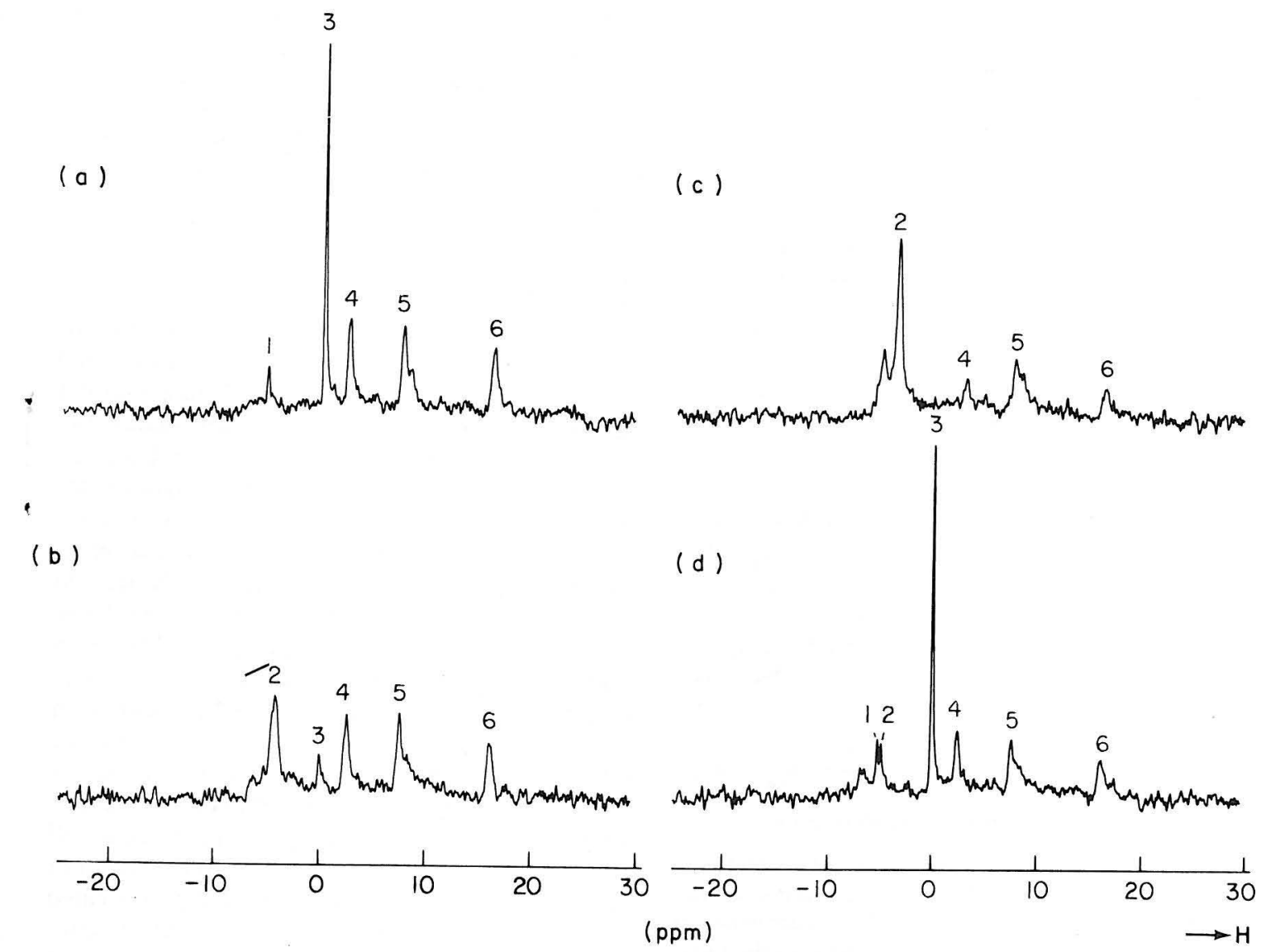

Figure $2{ }^{31} \mathrm{P}$ NMR spectra obtained (a) between 20 and $30 \mathrm{~min}$ of control perfusion in the presence of $1 \mathrm{mg} / 1$ nifedipine, (b) between 5 and $15 \mathrm{~min}$ of total ischemia, (c) between 20 and $30 \mathrm{~min}$ of total ischemia and (d) between 20 and $30 \mathrm{~min}$ of reperfusion. The spectra were obtained from 260 radiofrequency pulses. The arrow indicates the direction of increasing field strength. Numbered peaks: see legend to Fig. 1. Note the relative preservation of the $\beta$-ATP peak at the end of the ischemic period (spectrum c), and the decline of the Pi(int) peak and return of the CP peak during reperfusion.

(10 mmol/l). Myocardial CP and ATP levels were - measured by integrating the $C P$ and $\beta$-ATP signals. $\mathrm{CP}$ and ATP levels are expressed as percentage of the pre-ischemic control levels. Results are \& expressed as mean \pm S.E.M. of six experiments. Tests of significance were made using the unpaired t-test, taking $P=0.05$ as the limit of significance.

\section{Results}

Figures 1 and 2 show typical ${ }^{31}$ P NMR spectra of rat hearts during control perfusion, ischemia, and reperfusion. Figures 1 (a) and 2(a) represent control spectra, obtained during perfusion without and with nifedipine, respectively. During $30 \mathrm{~min}$ of total ischemia, there was complete depletion of myocardial high-energy phosphates in the untreated heart (Fig. $1 \mathrm{~b}$ and c). In the treated heart, $\mathrm{CP}$ and ATP levels decreased less rapidly (Fig. 2 b and c). In contrast with the untreated heart, the nifedipine-treated heart showed a marked decline of the Pi(int) peak and a concomitant return of the $\mathrm{CP}$ peak during reperfusion (Figs $1 \mathrm{~d}$ and $2 \mathrm{~d}$ ).

In the untreated hearts intracellular $\mathrm{pH}$ fell from $7 \cdot 11 \pm 0.03$ during control perfusion to $5.88 \pm 0.04$ at the end of the $30 \mathrm{~min}$ period of ischemia (Fig. $3)$. When $1 \mathrm{mg} / \mathrm{l}$ nifedipine was added to the perfusion fluid $10 \mathrm{~min}$ before the onset of ischemia, intracellular $\mathrm{pH}$ fell from $7 \cdot 11 \pm 0.03$ to $5 \cdot 95 \pm 0 \cdot 02$ during ischemia. Intracellular $\mathrm{pH}$ after $30 \mathrm{~min}$ of 

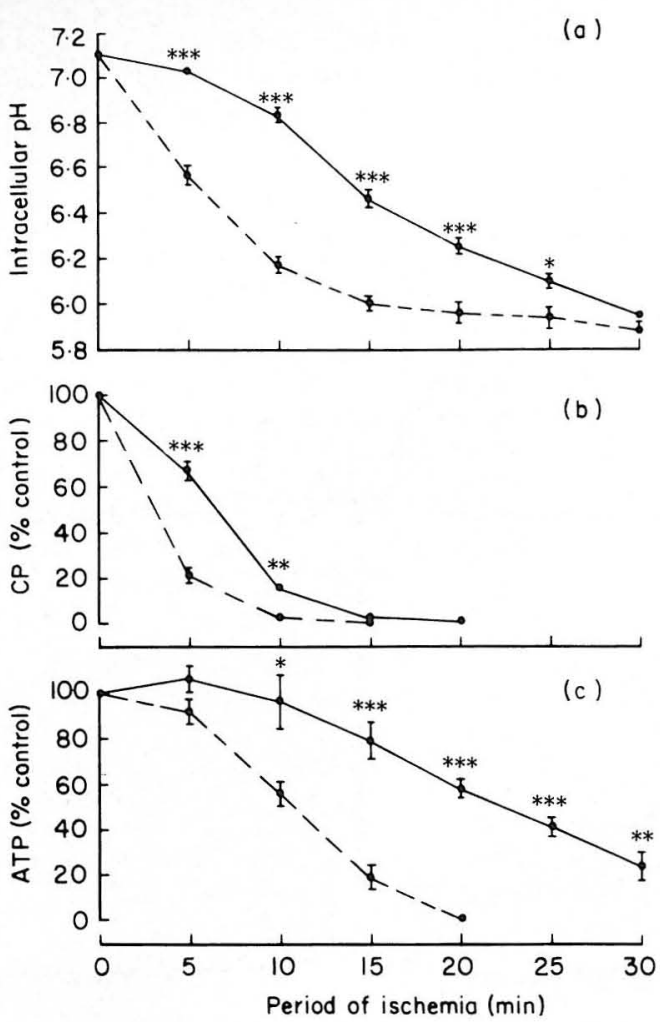

Figure 3 Time course of intracellular pH (a), and myocardial CP (b) and ATP (c) levels during 30 min of normothermic total ischemia. CP and ATP levels are expressed as percentage of the pre-ischemic control levels. In the treated hearts (-), $1 \mathrm{mg} / \mathrm{l}$ nifedipine was added to the perfusion fluid $10 \mathrm{~min}$ before the onset of ischemia. $-----=$ Control. Measurements were obtained from 130 -pulse spectra ( $5 \mathrm{~min})$, collected at $0-5,5-10,10-15$, $15-20,20-25$ and $25-30 \mathrm{~min}$ of ischemia. Each point is the mean \pm s.e.m. of six experiments. ${ }^{*} P<0.05$; ${ }^{* *} P<0.005 ;{ }^{* * *} P<0.001$.

ischemia did not differ significantly between the treated and untreated group. Until $25 \mathrm{~min}$ of ischemia, however, intracellular $\mathrm{pH}$ was significantly higher in the treated hearts $(P<0.001$ until $20 \mathrm{~min}$ of ischemia; $P<0.05$ at $25 \mathrm{~min}$ of ischemia).

During ischemia, CP levels decreased rapidly in both groups. Until $10 \mathrm{~min}$ of ischemia, however, the rate of decrease in $\mathrm{CP}$ content was lower in the treated than in the untreated hearts $(P<0.001$ at $5 \mathrm{~min}$ of ischemia; $P<0.05$ at $10 \mathrm{~min}$ of ischemia) (Figs 1b, 2b and 3). Myocardial CP content was depleted after $15 \mathrm{~min}$ of ischemia in the untreated hearts, and after $20 \mathrm{~min}$ of ischemia in the hearts treated with nifedipine.
After 20 min of ischemia, myocardial ATP content of the untreated hearts was depleted (Fig. 3),

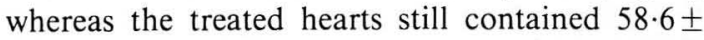
$4.4 \%$ of the pre-ischemic control level $(P<0.001)$. After $30 \mathrm{~min}$ of ischemia, ATP content in hearts that received nifedipine amounted to $23 \cdot 5 \pm 6 \cdot 2 \%$ of control (Figs 2c and 3).

\section{Discussion}

The results of the present study show that addition of $1 \mathrm{mg} / \mathrm{l}$ nifedipine to the perfusion fluid during $10 \mathrm{~min}$ before the onset of ischemia, protects the rat heart against some of the consequences of $30 \mathrm{~min}$ of normothermic global ischemia. Evidence of this protection was provided by a significantly lower rate of development of intracellular acidosis and a significantly lower rate of decrease in myocardial CP and ATP content during ischemia. At the end of the ischemic period, both treated and untreated hearts were depleted of CP. This is in agreement with the results of Flaherty et al[?], who used ${ }^{31}$ P NMR to study the effect of administration of a hyperkalemic cardioplegic solution during $60 \mathrm{~min}$ of hypothermic global ischemia in rabbit hearts. Although the rates of $\mathrm{CP}$ decline were dissimilar in the different groups of their study, all hearts were equally depleted of $\mathrm{CP}$ after $60 \mathrm{~min}$ of ischemia. Our finding that the nifedipine treated hearts contained $23 \cdot 5 \pm 6 \cdot 2 \%$ of control after $30 \mathrm{~min}$ of ischemia and showed a rapid recovery of $\mathrm{CP}$ and ATP levels during reperfusion (Fig $2 \mathrm{a}$ and d) lends support to the suggestion of Flaherty et al. ${ }^{[7]}$ that preservation of ATP content is the better metabolic correlate of functional recovery. We are aware that nifedipine was added in a high dose, and that the protective effect we observed may be a consequence of the cardioplegic effect of the drug.

Our data show a qualitative resemblance to the results of Nayler et al. ${ }^{[4]}$. In their study rabbits were injected subcutaneously twice daily with $2 \mathrm{mg} / \mathrm{kg}$ nifedipine for 4 to 5 days. The hearts were then isolated and made ischemic for $90 \mathrm{~min}$. Pretreating * the rabbits with nifedipine resulted in a significant preservation during normothermic ischemia of myocardial CP and ATP stores measured with the freeze-clamp method.

Magee et $a{ }^{10]}$ compared the effect of a cardioplegic dose of nifedipine, given at the onset of 90 min of hypothermic ischemic arrest, to hypothermia alone and to hypothermia with potassium cardioplegia. Isolated feline hearts were used in their study and the cardioplegic dose consisted of $10 \mathrm{ml}$ 
of perfusate containing $100 \mu \mathrm{g}$ of nifedipine. In our study, the hearts received a comparable dose of nifedipine during $10 \mathrm{~min}$ of perfusion with fluid containing $1 \mathrm{mg} / \mathrm{l}$ nifedipine before the onset of $30 \mathrm{~min}$ of normothermic ischemic arrest. Magee et al. ${ }^{[10]}$ demonstrated that nifedipine in a cardioplegic dose resulted in preservation of myocardial structure and function that was similar to that obtained with potassium cardioplegia.

In conclusion, our results indicate that nifedipine protects the myocardium against some of the metabolic consequences of ischemia and reperfusion. ${ }^{31} \mathrm{P}$ - NMR is a valuable tool for studying interventions designed to protect the myocardium.

The authors are very appreciative of the excellent technical assistance of D. de Moes and P. van der Meer.

\section{References}

[1] Hearse DJ, Garlick PB, Humphrey SM. Ischemic contracture of the myocardium: mechanisms and prevention. Am J Cardiol 1977; 39: 986-93.

[2] Williamson JR, Schaffer SW, Ford C, Safer B. Contribution of tissue acidosis to ischemic Injury in the perfused rat heart. Circulation 1976; 53: 13-14.
[3] Henry PD, Shuchleib R, Davis J, Weiss ES, Sobel BE Myocardial contracture and accumulation of mitochondrial calcium in ischemic rabbit heart. Am J Physiol 1977; 233: H677-84.

[4] Nayler WG, Ferrari R, Williams A. Protective effect of pretreatment with verapamil, nifedipine and propranolol on mitochondrial function in the ischemic and reperfused myocardium. Am J Cardiol 1980; 46: 242-8.

[5] Jong JW de, Harmsen E, Tombe PP de, Keijzer E. Nifedipine reduces adenine nucleotide breakdown in ischemic rat heart. Eur J Pharmacol 1982; 81: 89-96.

[6] Garlick PB, Radda GK, Seeley PJ. Studies of acidosis in the ischaemic heart by phosphorus nuclear magnetic resonance. Biochem J 1979; 184: 547-54.

[7] Flaherty JT, Weisfeldt ML, Bulkley BH, Gardner TJ, Gott VL, Jacobus WE. Mechanisms of ischemic myocardial cell damage assessed by phosphorus-31 nuclear magnetic resonance. Circulation 1982; 65: $561-71$.

[8] Langendorff $O$. Untersuchungen am überlebenden Säugetierherzen. Pfluegers Arch 1895; 61: 291-332.

[9] Clark RE, Christlieb IY, Spratt JA, et al. Myocardial preservation with nifedipine: a comparative study at normothermia. Ann Thorac Surg 1981; 31: 3-20.

[10] Magee PG, Flaherty JT, Bixler TJ, et al. Comparison of myocardial protection with nifedipine and potassium. Circulation 1979; 60: I151-7. 